\title{
Exploring how limiting the number of ball touches during small-sided games affects youth football players' performance across different age groups
}

International Journal of Sports Science \& Coaching $0(0) 1-13$

(C) The Author(s) 2021

Article reuse guidelines: sagepub.com/journals-permissions DOI: $10.1177 / 17479541211037001$ journals.sagepub.com/home/spo ๑SAGE

\author{
Diogo Coutinho' ${ }^{1,2,3}\left(\mathbb{D}\right.$, Bruno Gonçalves ${ }^{4,5,6}$ (D), Sara Santos ${ }^{1,2}$, \\ Bruno Travassos ${ }^{2,6,7}$, Hugo Folgado ${ }^{4,5}$ and Jaime Sampaio ${ }^{1,2}$
}

\begin{abstract}
This study explored how the number of allowed ball touches per player possession affected the performance of different age groups (U9, UII, UI3, UI5, UI7 and UI9) during a Gk + 4vs4+Gk small-sided games. Each day, players randomly performed the following three conditions (for a total of 6 days): i) free-play (FP); ii) maximum of 2 touches (2T); iii) I touch (I T). Players' positional data was used to compute time-motion and positional-related variables, while video analysis was used to capture technical performance.

In general, no effects were identified in relation to the players distances (team centroid, opponents' centroid, nearest teammate, and nearest opponent). There were small to moderate decreases in the longitudinal synchronization while playing with I T and $2 \mathrm{~T}$ in the U9 and UI7, but a moderate increase in the UI5. There was a general decrease in the distance covered and distance covered while running (small to moderate effects) when playing with limited touches in all age groups. Limiting the touches promoted small to moderate increases in the number of successful passes in the U9, UI5, and UI7 and a general increase in unsuccessful actions. Overall, playing with limited touches emphasized the passing skill while it also contributed to more unsuccessful actions and lower physical demands. As so, coaches may use the $2 \mathrm{~T}$ in young age groups (U9-UI3) as they seem less able to successfully cope with I T, while using I T in older age groups due to their higher ability to interact with environmental information.
\end{abstract}

\section{Keywords}

Global positioning system, soccer, tactics, time-motion analysis

\section{Introduction}

Small-sided games (SSG) are game-based practices regularly used by association football coaches to develop their players performance. ${ }^{1-3}$ Accordingly, SSG are characterized by practices performed often in small pitches, with adapted rules and involving a lower number of players compared to the official match. The reasons for such popularity have been linked with its ability to concurrently develop the players physical, technical and tactical behaviors and perceptual skills. ${ }^{2,4}$ In fact, SSG allows to recreate a similar perceptual-motor landscape that the players found during competitive matches, thus developing the players ability to couple their actions according to the available information on the environment. ${ }^{6,7}$ Indeed, one major feature of SSG is the possibility to emphasize specific
Reviewers: Matthias Kempe (University of Groningen, The Netherlands) Benedict Low (German Sport University Cologne, Germany)

'Department of Sports Sciences, Exercise and Health, University of Trásos-Montes and Alto Douro, Vila Real, Portugal

${ }^{2}$ Research Center in Sports Sciences, Health Sciences and Human Development, CIDESD, CreativeLab Research Community, Vila Real, Portugal

${ }^{3}$ University Institute of Maia, ISMAI, Maia, Portugal

${ }^{4}$ Departamento de Desporto e Saúde, Escola de Saúde e Desenvolvimento Humano, Universidade de Évora, Évora, Portugal ${ }^{5}$ Comprehensive Health Research Center (CHRC), Universidade de Évora, Évora, Portugal

${ }^{6}$ Portugal Football School, Portuguese Football Federation, Oeiras, Portugal

${ }^{7}$ Department of Sports Sciences, University of Beira Interior, Covilhã, Portugal

\section{Corresponding author:}

Diogo Coutinho, Department of Sports Sciences, Exercise and Health, University of Trás-os-Montes and Alto Douro, Vila Real, Portugal; Research Center in Sports Sciences, Health Sciences and Human Development, CIDESD, CreativeLab Research Community, Vila Real, Portugal; University Institute of Maia, ISMAI, Maia, Portugal.

Email: diogoamcoutinho@gmail.com 
information that will guide the players behavior towards specific goal-directed behaviors through the manipulation of specific task constraints. ${ }^{7,8}$ Constraints have been considered as boundaries conditions that shape the players movement behaviors, and can be divided into environmental, individual and task-related constraints. ${ }^{9}$ The latter refers to manipulations in the pitch size, players number, or game rules such as limiting the number of available touches (e.g., playing under two touches or one touch per player).

Based on the previous considerations, a wide scope of research has been exploring how different task constraints affected the players performance. Under this scope, the manipulation of the number of ball touches allowed per player during SSG have been one type of manipulation that have received considerable attention, mainly from the physical perspective. Accordingly, international-level players shown more total distance covered, distance covered at high intensity and sprinting when the number of touches was limited during a possession (4vs $4+4$ neutral players) SSG.${ }^{10,11}$ Similarly, a more recent study also using professional players during a 4vs4 SSG with the aim of score in two small targets also found higher distance covered while walking when playing under 1 touch (1 T) and higher distance at moderate intensities under 2 touches $(2 \mathrm{~T}) .^{12}$ Other study using semi-professional players during a $4 \mathrm{vs} 4$ possession SSG also found higher intensities when playing with lower number of touches $(1 \mathrm{~T}$ or $2 \mathrm{~T})$ allowed. ${ }^{13}$ However, evidences from players with lower experience seems to not be consistent as it have been shown higher intensities when playing without touches limitations in both 6vs6 under possession purposes with semiprofessional players ${ }^{14}$ or during Gk $+6 \mathrm{vs} 6+\mathrm{Gk}$ SSG with amateur players. ${ }^{15}$ Altogether, the findings from the previous studies suggest that different physical responses emerge when performing the same task constraint (limiting the number of ball touches allowed) from players belonging to different experience levels (professional, semi-professional and amateur). Considering this point-of-view, it would be important to understand how this constraint affects youth players physical performance as it consists in one of the most common rules used nowadays during the players developmental stages. Accordingly, it may be possible that youth players reveal lower physical demands when playing under limited touches due to their lower perceptualmotor skills, when compared with expert players.

Coaches also limit the number of touches allowed during SSG to impose higher perceptual demands on the players and refine their technical performance. Under this scope, the available research has shown that international-level players decrease the percentage of successful passes when playing under limited touches, especially $1 \mathrm{~T}$, despite the higher number of ball possessions. ${ }^{10,11}$ Similarly, semi-professional players also revealed a lower percentage of successful passes and an increase in the number of ball losses when playing with limited touches, mainly at $1 \mathrm{~T} .{ }^{13}$ These results seem to be linked with the lower time to decide and scan the environment when playing under such rules. That is, in 1 touch condition, the players have to decide what to do until the last moment before touching the ball while, without touch restrictions the player may stay on the ball, protect it, or travel with it to explore different opportunities for action. Considering this increased perceptual demands, $t$ may be expected that these effects may be exacerbated in players with lower experience ${ }^{16}$ such as youth players. . In addition, players under different stages of development (e.g., U13 and U19) may reveal different adaptations to this rule constraint manipulation. However, further research is required to clarify these assumptions. Overall, distinct physical, technical and positional behaviors seem to emerge as result of different task constraint manipulations. Despite the considerable number of studies exploring the effects of limiting the number of touches, mostly were related with physical and technical performance, and to the best of our knowledge there is no research exploring it effects on the players positional behavior. Under this perspective, variables such as the distance from players to their team centroid, opponent team centroid $^{17}$ nearest teammate, nearest defender ${ }^{18}$ length per width ratio (lpwratio), ${ }^{19,20}$ spatial exploration index $(\mathrm{SEI})^{21}$ or the time that players spent synchronized in the longitudinal and lateral direction ${ }^{22,23}$ have been used as tactical-positional variables that are sensitive to capture changes in players behavior according to manipulations in task constraints. Exploring how these positional variables are affected by the limitations in ball touches may provide additional insights that would allow to better frame its use during the training sessions.

In addition, players also seem to reveal different responses as result of their experience, and so, it would be important to have a deeper understanding on how changing the number of touches allowed affects players belonging to different age groups. Based on the previous considerations, this study aimed to explore how the number of allowed ball touches (free play, 2 touches and 1 touch) affected the tactical-positional, physical and technical behavior of players belonging to different age groups (U9, U11, U13, U15, U17 and U19) during a Gk $+4 \mathrm{vs} 4+$ Gk SSG.

\section{Methods}

\section{Participants}

A total of one hundred and fourteen youth football players from the same club participated in this study 
Table I. Participants characteristics.

\begin{tabular}{|c|c|c|c|c|c|c|c|}
\hline Age groups & $\mathrm{N}$ & Age (years) & Height (cm) & Mass (kg) & $\begin{array}{l}\text { Playing } \\
\text { experience } \\
\text { (years) }\end{array}$ & $\begin{array}{l}\text { Training sessions } \\
\text { per week (n) }\end{array}$ & Competitive matches per week (n) \\
\hline Under-9 & 20 & $7.9 \pm 0.9$ & $128.5 \pm 6.5$ & $29.4 \pm 8.8$ & $2.7 \pm 1.1$ & 2 sessions of $90-\mathrm{min}$ & I friendly $(G k+4 v s 4+G K)$ \\
\hline Under-II & 20 & $9.5 \pm 0.9$ & $138.8 \pm 7.9$ & $33.7 \pm 6.8$ & $3.9 \pm 1.2$ & 3 sessions of $90-\mathrm{min}$ & I friendly (Gk+7vs7+GK) \\
\hline Under-13 & 21 & $11.6 \pm 0.8$ & $147.3 \pm 7.6$ & $40.5 \pm 7.6$ & $4.9 \pm 2.0$ & 3 sessions of $90-\mathrm{min}$ & I competitive (Gk+9vs9+GK) \\
\hline Under-I5 & 18 & $13.9 \pm 0.6$ & $166.4 \pm 10.9$ & $48.8 \pm 8.6$ & $6.8 \pm 2.5$ & 3 sessions of $90-\mathrm{min}$ & I competitive $(\mathrm{Gk}+\mathrm{IOvs}$ I0+GK) \\
\hline Under-17 & 19 & $16.2 \pm 0.7$ & $|7| .8 \pm 7.7$ & $65.4 \pm 6.5$ & $7.9 \pm 2.8$ & 4 sessions of $90-\mathrm{min}$ & I competitive $(\mathrm{Gk}+\mathrm{IOvs}$ I0+GK) \\
\hline Under-19 & 16 & $17.9 \pm 0.4$ & $174.4 \pm 5.8$ & $66.9 \pm 5.8$ & $9.5 \pm 2.1$ & 4 sessions of $90-\mathrm{min}$ & I competitive (Gk+10vs I0+GK) \\
\hline
\end{tabular}

(Table 1). Players were engaged in two to four training sessions per week (90 to 105 minutes per session) and participated in a match during the weekend. Goalkeepers were part of the study but were excluded from the data analysis, since their positioning is very restricted to a specific pitch area and their game dynamics are different from the outfield players. An informed consent was provided to the coaches, players, and their parents, as well as to the club, before the beginning of the study. All participants were notified that they could withdraw from the study at any time. The study protocol followed the guidelines and was approved by the local Ethics Committee and conformed to the recommendations of the Declaration of Helsinki.

\section{Study design}

The study design was based on a repeated measure approach under three experimental conditions: (i) free play (FP), where the players did not have any limit in the number of ball touches; (ii) 2 touches $(2 \mathrm{~T})$, in which the players were only allowed to perform a maximum of two ball touches per ball possession; and (iii) 1 touch $(1 \mathrm{~T})$, where the players were only allowed to perform one ball touch per ball possession. For this purpose, the games were played using a $\mathrm{Gk}+4 \mathrm{vs} 4+\mathrm{Gk}$, as one of the most common gamebased formats used in association football. ${ }^{10}$

\section{Procedures}

The study was developed over a two-week period during the middle of in-season competitive period. A total of six non-consecutive sessions were used to collect players performance during the SSG, where the players were exposed to all the three conditions on each testing day. No familiarization session was performed, as the players in this study were already familiarized with these manipulations (all age groups were exposed at least three times in the month previous to the data collection). In all testing days and for each age group, the session started at the same time of the day, to avoid the effects of circadian rhythms on the results, and over similar weather conditions (atmospheric temperature $16 \pm 5^{\circ} \mathrm{C}$ ). Before the experimental conditions, the players performed a 15-min warm-up based on lowintensity running and a 4-a-side ball possession game.

\section{Experimental task}

For each testing day, the head coach from each age group selected eight players that allowed to create two balanced teams considering the coach perception of the players physical, technical, tactical and decisionmaking skills. While there were variations on the team's composition over the six testing days, to guarantee a higher data generalization and age group squad participation, for each testing day the teams and players were kept constant across conditions. Each day players performed three bouts of 4-min interspersed with a 2-min passive recovery in between, where each bout consisted in one of the three conditions (free play, 2 touches, 1 touch) played in a random order. The SSG consisted on a Gk $+4 \mathrm{vs} 4+$ Gk SSG on a $40 \times 30 \mathrm{~m}$ artificial turf pitch (length $\mathrm{x}$ width; $150 \mathrm{~m}^{2}$ relative playing space per player). The pitch external boundaries were defined using markers at each 5 meters as previous research reported distinct physical, technical and tactical behaviors as result of the type of pitch external marking lines. ${ }^{22}$ Several balls were placed around the field to ensure its replacement as fast as possible, decreasing the time that the ball was out of play. No coach feedback or encouragement was allowed during the conditions. The players were encouraged to hydrate with water before the SSG and in-between the bouts. Apart from the off-side rule that was not applied and the restart of the game by the goalkeeper that conceded a goal to ensure a fast restart, all the remaining rules were played according to the FIFA football rules.

\section{Data collection}

Tactical variables. Positional data during SSG were gathered using $5 \mathrm{~Hz}$ global positioning system (GPS) units (SPI-PRO, GPSports, Canberra, ACT, Australia). 
The players' latitude and longitude coordinates obtained through games were exported and computed using appropriate routines in Matlab ${ }^{\circledR}$ (MathWorks, Inc., Massachusetts, USA). Additionally, missed data were re-sampled and filtered using a $3 \mathrm{~Hz}$ Butterworth low pass filter. Following this procedure, the data were converted to meters using the Universal Transverse Mercator (UTM) coordinate system and a rotational matrix was applied to adjust the players displacement data, pitch length and width with the appropriate $\mathrm{x}$ and $y$-axis. This procedure was carried out by the data retrieved from 4 GPS units placed on each pitch corners please check reference Folgado, Duarte (24 for data correction guidelines).

The players positional data were used to calculate the absolute distances from each player to the team centroid (i.e., variable that represent the mean position from all outfield players at every timeframe) and the absolute distances from each player to the opposing team centroid. Also, it was assessed the absolute distances from each player to the nearest teammate and nearest opponent. ${ }^{17}$ Accordingly, the previous variables have been used to analyze how players positional dynamics is affected by changes in task constraints. ${ }^{17,24}$ The length per width ratio (lpwratio) was used to understand players space occupation and was processed based on each team maximum and lowest length and width values for every frame, from which was calculated the ratio. ${ }^{19,20}$ The players spatial exploration index (SEI) was computed, which represents the amount of area explored by each player. This variable consists in processing the average position from each player on the pitch, then computing the distance from all the positioning during the time-series to this average position, and lastly computing the mean value from all the obtained distances. ${ }^{21}$ This variable has been used to understand how players area exploration is modified according to manipulations in task constraints ${ }^{21}$ or following training interventions $^{25}$ where higher values suggest a higher individual area explored. In addition, the intra-team coordination tendencies were measured based on the time that the dyads from each team spent synchronized in both longitudinal and lateral directions. These two last variables have been considered as important tactical indicators ${ }^{22}$ as usually, better tactical performances are characterized by higher values. ${ }^{18,26,27}$ To process the players coordination tendencies, the Hilbert transform was used ${ }^{28}$ and applied to all possible dyads $(n=6)$ during players longitudinal (x-axis) and lateral (y-axis) movement directions. The near-in-phase synchronization of each dyad was quantified by the percent of time spent between $-30^{\circ}$ to $30^{\circ}$ bin (near-in-phase mode of coordination). ${ }^{26}$ The selected interval was used based on previous research, that found in-phase relations tendencies as the most common mode of coordination. ${ }^{26,29,30}$
Physical variables. The total distance covered and distance at different speed zones categories were considered as the following as identified in previous studies analyzing youth players physical performance during SSG: ${ }^{22,31,32}$ i) total distance covered; ii) distance covered while walking $(0.0-3.5 \mathrm{~km} / \mathrm{h})$; iii) jogging $(3.6-$ $14.3 \mathrm{~km} / \mathrm{h})$; and iv) running $(>14.4 \mathrm{~km} / \mathrm{h})$. In this study, the distance covered while sprinting was not considered as the small pitch size may not allow the players to cover the distance at high speeds. ${ }^{22,33}$

Technical variables. The SGG were recorded using a digital video camera, Sony NV-GS230, that was fixed at a 2-m height and aligned in the midfield part of the pitch. Then, the video files were downloaded to a computer and a notational analysis was performed using the LongoMatch software (Longomatch, version 1.3.7., Fluendo). The following individual performance variables were collected: successful and unsuccessful passes, successful dribbles, shots-on-target and goals. ${ }^{34}$ The videos were analyzed by an experienced performance analyst, and the data reliability (technical-related) was inspected by retesting 2 bouts per condition (free play, 2 touches, 1 touch; $\sim 33 \%$ of the sample). The intraclass correlation was deemed as high $(>0.90){ }^{35}$

\section{Statistical analysis}

The data were presented as means $(\mathrm{M}) \pm$ standard deviations (SD). All data were assessed for outliers and assumptions of normality using the Shapiro-Wilk Test. Based on the data normality, two types of tests were used: repeated measures analysis of variance (ANOVA) while the non-parametric Friedman ANOVA test was used for the variables that did not show a normal distribution. Statistical significance was set at $\mathrm{p}<.05$ and calculations were carried out using SPSS software V24.0 (IBM SPSS Statistics for Windows, Armonk, NY: IBM Corp.).

Differences in group means were expressed in raw data units with $90 \%$ confidence limits. Thresholds for effect size statistics were: $<0.2$, trivial; $<0.6$, small; $<1.20$, moderate; $<2.0$, large; and $>2.0$, very large. ${ }^{36}$ These statistical computations were processed with a specific post-only crossover spreadsheet for each age group. ${ }^{37}$

\section{Results}

\section{Effects of manipulating the number of touches on the tactical-positional behavior}

The effects on the positional variables when manipulating the number of touches (free vs $1 / 2$ touches) on the different age groups are presented on the Table 2 
Table 2. Descriptive and statistical analysis for the tactical-positional variables according to SSG rule and age groups.

\begin{tabular}{|c|c|c|c|c|c|c|c|}
\hline & & \multicolumn{3}{|l|}{ SSG conditions } & \multicolumn{2}{|c|}{ Difference in means $( \pm 90 \% \mathrm{CL})$} & \multirow[b]{2}{*}{$p$} \\
\hline \multicolumn{2}{|c|}{ Positional Variables } & $\begin{array}{l}\text { Free } \\
(\text { Mean } \pm S D)\end{array}$ & $\begin{array}{l}2 \text { Touches } \\
\text { (Mean } \pm S D)\end{array}$ & $\begin{array}{l}\text { I Touch } \\
\text { (Mean } \pm \text { SD) }\end{array}$ & $\begin{array}{l}\text { Free vs } \\
2 \text { Touches }\end{array}$ & $\begin{array}{l}\text { Free vs } \\
\text { I Touch }\end{array}$ & \\
\hline \multirow[t]{8}{*}{ U9 } & Distance to team centroid $(\mathrm{m})$ & $5.12 \pm 1.27$ & $5.16 \pm 1.39$ & $5.42 \pm 1.73$ & $0.04 ; \pm 0.3$ & $0.30 ; \pm 0.36$ & $>0.05$ \\
\hline & Distance to opposing team centroid $(\mathrm{m})$ & $6.45 \pm 1.57$ & $6.60 \pm 2.07$ & $6.66 \pm 2.23$ & $0.15 ; \pm 0.35$ & $0.2 \mathrm{I} ; \pm 0.40$ & $>0.05$ \\
\hline & Distance to nearest teammate $(\mathrm{m})$ & $5.01 \pm 1.29$ & $5.05 \pm 1.42$ & $5.23 \pm 1.82$ & $0.04 ; \pm 0.31$ & $0.22 ; \pm 0.38$ & $>0.05$ \\
\hline & Distance to the nearest opponent $(\mathrm{m})$ & $4.12 \pm 0.94$ & $4.33 \pm 1.29$ & $4.23 \pm 1.32$ & $0.22 ; \pm 0.23$ & $0.11 ; \pm 0.25$ & $>0.05$ \\
\hline & Length/width ratio $(\mathrm{m})$ & $1.45 \pm 0.82$ & $1.53 \pm 0.61$ & $\mathrm{I} .57 \pm 0.67$ & $0.08 ; \pm 0.21$ & $0.12 ; \pm 0.25$ & $>0.05$ \\
\hline & Spatial exploration index (SEI, m) & $9.41 \pm 1.86$ & $9.48 \pm 2.22$ & $8.57 \pm 1.53$ & $0.08 ; \pm 0.38$ & $-0.84 ; \pm 0.38$ & $<0.0 \mathrm{I}^{\mathrm{a}}$ \\
\hline & Longitudinal synchronization (\%) & $58.90 \pm 14.74$ & $58.91 \pm 18.61$ & $49.82 \pm 16.50$ & $0.01 ; \pm 3.92$ & $-9.09 ; \pm 3.47$ & $<0.01^{\mathrm{a}}$ \\
\hline & Lateral synchronization (\%) & $49.43 \pm 14.29$ & $49.84 \pm 15.50$ & $48.72 \pm 14.62$ & $0.42 ; \pm 3.45$ & $-0.7 I ; \pm 3.15$ & $>0.05$ \\
\hline \multirow[t]{8}{*}{ UII } & Distance to team centroid $(\mathrm{m})$ & $5.59 \pm 0.96$ & $5.57 \pm 1.13$ & $5.50 \pm \mathrm{I} .14$ & $-0.02 ; \pm 0.24$ & $-0.09 ; \pm 0.19$ & $>0.05$ \\
\hline & Distance to opposing team centroid $(\mathrm{m})$ & $6.61 \pm 1.26$ & $6.61 \pm 1.47$ & $6.51 \pm 1.32$ & $0.0 ; \pm 0.29$ & $-0.1 ; \pm 0.24$ & $>0.05$ \\
\hline & Distance to nearest teammate $(\mathrm{m})$ & $6.03 \pm 1.0$ & $5.92 \pm 1.00$ & $5.89 \pm 1.21$ & $-0.1 \mathrm{I} ; \pm 0.2 \mathrm{I}$ & $-0.14 ; \pm 0.22$ & $>0.05$ \\
\hline & Distance to the nearest opponent $(\mathrm{m})$ & $4.16 \pm 0.80$ & $4.24 \pm 0.83$ & $4.16 \pm 0.76$ & $0.08 ; \pm 0.19$ & $-0.01 ; \pm 0.16$ & $>0.05$ \\
\hline & Length/width ratio $(\mathrm{m})$ & $1.05 \pm 0.33$ & $0.94 \pm 0.24$ & $0.99 \pm 0.27$ & $-0.1 \mathrm{I} ; \pm 0.08$ & $-0.06 ; \pm 0.08$ & $>0.05$ \\
\hline & Spatial exploration index (SEI, m) & $8.67 \pm 1.84$ & $8.00 \pm 1.32$ & $9.35 \pm 1.10$ & $-0.67 ; \pm 0.54$ & $0.69 ; \pm 0.52$ & $<0.00 \mathrm{I}^{\mathrm{a}, \mathrm{b}}$ \\
\hline & Longitudinal synchronization (\%) & $65.06 \pm 10.32$ & $63.86 \pm 14.90$ & $65.61 \pm 13.04$ & $-\mathrm{I.19} ; \pm 4.07$ & $0.55 ; \pm 3.22$ & $>0.05$ \\
\hline & Lateral synchronization (\%) & $53.49 \pm 12.38$ & $49.26 \pm 17.80$ & $53.37 \pm 14.27$ & $-4.23 ; \pm 3.01$ & $-0.11 ; \pm 3.36$ & $>0.05$ \\
\hline \multirow[t]{8}{*}{ UI3 } & Distance to team centroid $(\mathrm{m})$ & $6.45 \pm 1.28$ & $6.68 \pm 1.15$ & $6.52 \pm 1.18$ & $0.23 ; \pm 0.22$ & $0.08 ; \pm 0.22$ & $>0.05$ \\
\hline & Distance to opposing team centroid $(\mathrm{m})$ & $7.19 \pm 1.61$ & $7.29 \pm 1.44$ & $7.54 \pm 1.70$ & $0.1 ; \pm 0.26$ & $0.34 ; \pm 0.28$ & $>0.05$ \\
\hline & Distance to nearest teammate $(\mathrm{m})$ & $7.21 \pm 1.02$ & $7.47 \pm 0.90$ & $7.37 \pm 0.94$ & $0.26 ; \pm 0.23$ & $0.16 ; \pm 0.22$ & $>0.05$ \\
\hline & Distance to the nearest opponent $(\mathrm{m})$ & $4.18 \pm 0.79$ & $4.25 \pm 0.66$ & $4.35 \pm 0.99$ & $0.07 ; \pm 0.16$ & $0.17 ; \pm 0.22$ & $>0.05$ \\
\hline & Length/width ratio $(\mathrm{m})$ & $0.89 \pm 0.19$ & $0.92 \pm 0.19$ & $0.92 \pm 0.22$ & $0.03 ; \pm 0.06$ & $0.02 ; \pm 0.06$ & $>0.05$ \\
\hline & Spatial exploration index (SEI, m) & $7.96 \pm 1.27$ & $7.74 \pm 1.06$ & $7.52 \pm 1.02$ & $-0.22 ; \pm 0.33$ & $-0.44 ; \pm 0.30$ & $>0.05$ \\
\hline & Longitudinal synchronization (\%) & $56.91 \pm 13.10$ & $57.53 \pm 14.36$ & $63.06 \pm 11.58$ & $0.62 ; \pm 3.46$ & $6.15 ; \pm 3.37$ & $<0.0 \mathrm{I}^{\mathrm{a}}$ \\
\hline & Lateral synchronization (\%) & $47.30 \pm 13.93$ & $45.53 \pm 12.43$ & $44.06 \pm 10.7$ & $-1.78 ; \pm 2.64$ & $-3.24 ; \pm 2.98$ & $>0.05$ \\
\hline \multirow[t]{8}{*}{ UI5 } & Distance to team centroid $(\mathrm{m})$ & $5.89 \pm 1.15$ & $6.06 \pm 1.11$ & $5.97 \pm 1.21$ & $0.17 ; \pm 0.15$ & $0.08 ; \pm 0.19$ & $>0.05$ \\
\hline & Distance to opposing team centroid $(\mathrm{m})$ & $6.46 \pm 1.52$ & $6.62 \pm 1.40$ & $6.46 \pm 1.44$ & $0.16 ; \pm 0.19$ & $0.0 ; \pm 0.25$ & $>0.05$ \\
\hline & Distance to nearest teammate $(\mathrm{m})$ & $6.57 \pm 0.72$ & $6.79 \pm 0.69$ & $6.62 \pm 0.84$ & $0.22 ; \pm 0.14$ & $0.05 ; \pm 0.18$ & $>0.05$ \\
\hline & Distance to the nearest opponent $(\mathrm{m})$ & $3.86 \pm 0.63$ & $4.05 \pm 0.63$ & $3.89 \pm 0.60$ & $0.19 ; \pm 0.13$ & $0.03 ; \pm 0.13$ & $<0.05^{b}$ \\
\hline & Length/width ratio $(\mathrm{m})$ & $0.86 \pm 0.19$ & $0.86 \pm 0.18$ & $0.88 \pm 0.19$ & $0.0 ; \pm 0.05$ & $0.02 ; \pm 0.05$ & $>0.05$ \\
\hline & Spatial exploration index (SEI, m) & $7.80 \pm 1.04$ & $8.26 \pm 1.12$ & $8.28 \pm 0.96$ & $0.46 ; \pm 0.40$ & $0.47 ; \pm 0.36$ & $>0.05$ \\
\hline & Longitudinal synchronization (\%) & $56.60 \pm 10.35$ & $65.92 \pm 8.88$ & $65.53 \pm 10.87$ & $9.15 ; \pm 2.67$ & $8.93 ; \pm 2.45$ & $<0.00 \mathrm{I}^{\mathrm{a}, \mathrm{b}}$ \\
\hline & Lateral synchronization (\%) & $41.33 \pm 11.33$ & $42.89 \pm 12.58$ & $46.13 \pm 11.42$ & $1.76 ; \pm 2.77$ & $4.80 ; \pm 2.71$ & $<0.05^{\mathrm{a}}$ \\
\hline \multirow[t]{8}{*}{ UI7 } & Distance to team centroid $(\mathrm{m})$ & $5.98 \pm 1.04$ & $6.0 \pm 0.95$ & $6.17 \pm 1.10$ & $0.0 \mathrm{I} ; \pm 0.23$ & $0.19 ; \pm 0.16$ & $>0.05$ \\
\hline & Distance to opposing team centroid $(\mathrm{m})$ & $6.74 \pm 1.42$ & $6.88 \pm 1.59$ & $6.95 \pm 1.52$ & $0.14 ; \pm 0.26$ & $0.21 ; \pm 0.26$ & $>0.05$ \\
\hline & Distance to nearest teammate $(\mathrm{m})$ & $6.60 \pm 0.74$ & $6.59 \pm 0.73$ & $6.76 \pm 0.82$ & $0.0 ; \pm 0.2$ & $0.16 ; \pm 0.17$ & $>0.05$ \\
\hline & Distance to the nearest opponent $(\mathrm{m})$ & $4.42 \pm 0.63$ & $4.35 \pm 0.68$ & $4.58 \pm 0.71$ & $-0.07 ; \pm 0.13$ & $0.16 ; \pm 0.09$ & $>0.05$ \\
\hline & Length/width ratio $(\mathrm{m})$ & $0.82 \pm 0.16$ & $0.81 \pm 0.18$ & $0.88 \pm 0.17$ & $-0.02 ; \pm 0.05$ & $0.06 ; \pm 0.05$ & $>0.05$ \\
\hline & Spatial exploration index (SEI, m) & $8.04 \pm 0.97$ & $8.17 \pm 1.21$ & $7.65 \pm 0.92$ & $0.13 ; \pm 0.30$ & $-0.39 ; \pm 0.27$ & $<0.05^{\mathrm{a}}$ \\
\hline & Longitudinal synchronization (\%) & $56.72 \pm 9.97$ & $53.40 \pm 13.12$ & $49.67 \pm 10.75$ & $-3.32 ; \pm 3.03$ & $-7.05 ; \pm 2.55$ & $<0.00 \mathrm{I}^{\mathrm{a}}$ \\
\hline & Lateral synchronization (\%) & $34.15 \pm 12.20$ & $38.73 \pm 13.08$ & $35.62 \pm 13.19$ & $4.58 ; \pm 3.09$ & $1.47 ; \pm 3.08$ & $<0.05^{b}$ \\
\hline \multirow[t]{8}{*}{ U19 } & Distance to team centroid $(\mathrm{m})$ & $6.38 \pm 1.11$ & $6.43 \pm 0.94$ & $6.37 \pm 1.05$ & $0.05 ; \pm 0.25$ & $-0.0 \mathrm{I} ; \pm 0.28$ & $>0.05$ \\
\hline & Distance to opposing team centroid $(\mathrm{m})$ & $7.11 \pm 1.44$ & $7.16 \pm 1.38$ & $6.95 \pm 1.26$ & $0.05 ; \pm 0.32$ & $-0.17 ; \pm 0.34$ & $>0.05$ \\
\hline & Distance to nearest teammate $(\mathrm{m})$ & $6.99 \pm 0.86$ & $7.1 \pm 0.66$ & $6.95 \pm 0.77$ & $0.12 ; \pm 0.23$ & $-0.04 ; \pm 0.25$ & $>0.05$ \\
\hline & Distance to the nearest opponent $(\mathrm{m})$ & $4.59 \pm 0.65$ & $4.68 \pm 0.55$ & $4.54 \pm 0.57$ & $0.09 ; \pm 0.15$ & $-0.05 ; \pm 0.18$ & $>0.05$ \\
\hline & Length/width ratio $(\mathrm{m})$ & $0.93 \pm 0.14$ & $0.72 \pm 0.19$ & $0.76 \pm 0.16$ & $0.02 ; \pm 0.05$ & $0.05 ; \pm 0.05$ & $>0.05$ \\
\hline & Spatial exploration index (SEI, m) & $7.8 \pm 1.04$ & $7.57 \pm 1.13$ & $8.0 \pm 1.01$ & $-0.23 \pm 0.33$ & $0.19 \pm 0.31$ & $>0.05$ \\
\hline & Longitudinal synchronization (\%) & $48.15 \pm 12.87$ & $47.26 \pm 10.64$ & $45.89 \pm 12.61$ & $-0.89 ; \pm 2.93$ & $-2.25 ; \pm 2.87$ & $>0.05$ \\
\hline & Lateral synchronization (\%) & $30.52 \pm 12.25$ & $25.99 \pm 10.69$ & $34.00 \pm 13.64$ & $-4.53 ; \pm 3.25$ & $3.48 ; \pm 3.82$ & $<0.0 \mathrm{I}^{\mathrm{b}}$ \\
\hline
\end{tabular}

CL: confidence limits.

${ }^{a}$ Significant differences between free and I touch $(\mathrm{p} \leq .05)$.

${ }^{b}$ Significant differences between free and 2 touches $(p \leq .05)$.

and Figure 1. Generally, players distances to the nearest teammate, nearest opponent, team centroid and opponent team centroid revealed no differences, apart from the distance to the nearest opponent in the U15 that revealed higher values under $2 \mathrm{~T}[0.3$ (0.1 to 0.5$)$,
Cohen's d with $90 \%$ confidence intervals, $\mathrm{X}^{2}=8.8$, $p<0.01]$ compared to the free condition. Also, no effects were identified in the lpwratio. In contrast, from the longitudinal perspective, the results shown small decreases in the U9 when playing under $1 \mathrm{~T}$ 


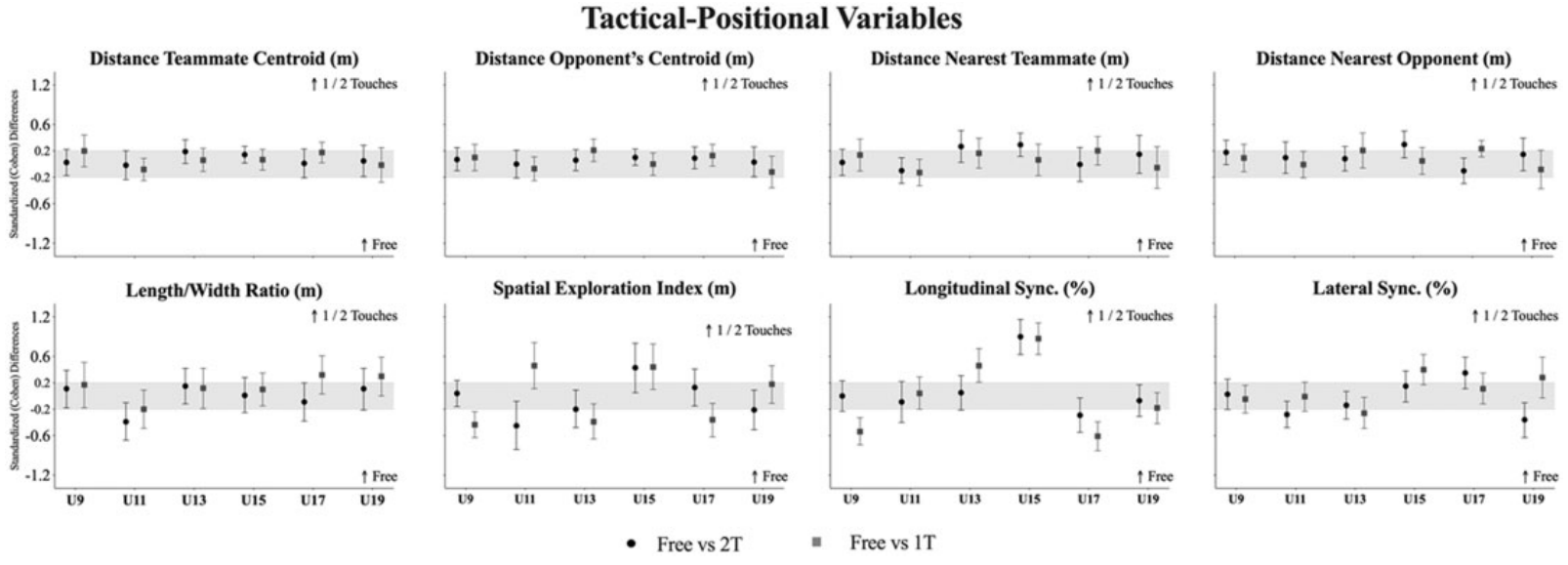

Figure I. Standardized (Cohen) differences in tactical-positional variables according to the rules modification (free, $2 \mathrm{~T}$, I T) in the different age groups. Error bars indicate uncertainty in the true mean changes with $90 \%$ confidence intervals.

$\left[-0.5(-0.7\right.$ to -0.3$\left.), \mathrm{X}^{2}=13.4, p<0.01\right]$, and small to moderate decreases in the U17 [ $-0.3(-0.6$ to -0.0$)$ and $-0.6(-0.8$ to -0.4$) 2 \mathrm{~T}$ and $1 \mathrm{~T}$ respectively, $F=9.15, P<0.001]$, while small increases when playing with $1 \mathrm{~T}$ during the U13 [0.5 (0.2 to 0.7$), F=5.55$, $p<0.01]$ and moderate increases when limiting the touches in the U15 [0.9 (0.6 to 1.2$)$ and 0.9 (0.6 to 1.1) $2 \mathrm{~T}$ and $1 \mathrm{~T}$ respectively, $\left.\mathrm{X}^{2}=2494, p<0.001\right]$. The effects of the players lateral synchronization were only evident on the older age groups. Accordingly, there were small increases in the team lateral synchronization when playing with $2 \mathrm{~T}$ in the U17 [0.4 (0.1 to $0.6), F=3.18, p \leq 0.05$ ], while small decreases in the U19 [ $-0.4(-0.6$ to -0.1$), F=7.15, p<0.01]$. Also, it was found small increases when playing with $1 \mathrm{~T}$ in the $\mathrm{U} 15$ [0.4 (0.2 to 0.6$), F=4.55, p \leq 0.05]$, and U19 [0.3 (0.0 to 0.6$)]$ age groups. Lastly, different trends emerged in the spatial exploration index, as there were small decreases when playing with $2 \mathrm{~T}$ in the U11 $[-0.5$ $(-0.8$ to -0.1$\left.), \mathrm{X}^{2}=24.1, p<0.001\right]$, and there were small decreases while playing with $1 \mathrm{~T}$ in the U9 $[-0.4$ $(-0.6$ to -0.2$\left.), \mathrm{X}^{2}=12.9, p<0.01\right]$ and $\mathrm{U} 17[-0.4(-0.6$ to -0.1$\left.), \mathrm{X}^{2}=3.18, p \leq 0.05\right]$. In contrast, there were small increases while playing with $1 \mathrm{~T}$ in the U11.

\section{Effects of manipulating the number of touches on the physical performance}

The effects on the physical variables when manipulating the number of touches (free vs $1 / 2$ touches) on the different age groups are presented on the Table 3 and Figure 2. From the physical perspective, there were clear trends in the total distance covered as there were small to moderate decreases when limiting the number of touches in all age groups [U9, $-0.3(-0.5$ to -0.2$)$ and $-0.5(-0.7$ to -0.4$), 2 \mathrm{~T}$ and $1 \mathrm{~T}$ respectively, $F=13.4, p<0.001$; U11, $-1.1(-1.3$ to -0.9$)$ and $-1.2(-1.4$ to -1.0$), 2 \mathrm{~T}$ and $1 \mathrm{~T}$ respectively, $\mathrm{X}^{2}=48.8, p<0.001$; U13, $-1.0(-1.3$ to -0.8$)$ under $1 \mathrm{~T}, \mathrm{X}^{2}=32.4, p<0.001 ; \mathrm{U} 15,-0.5(-0.7$ to -0.3$)$ and $-0.4(-0.6$ to -0.2$), 2 \mathrm{~T}$ and $1 \mathrm{~T}$ respectively, $F=10.2, \quad p<0.001 ; \mathrm{U} 17,-0.5 \quad(-0.7$ to -0.2$)$, for $1 \mathrm{~T}, F=5.17, p<0.01 ; \mathrm{U} 19,-0.3(-0.5$ to -0.1$)$ for $1 \mathrm{~T}, F=3.64, p \leq 0.05]$. Also, small to moderate increases in the distance covered while walking were identified for all age groups [U9, $0.4(0.2$ to 0.5$)$ and 0.6 (0.4 to 0.8$), 2 \mathrm{~T}$ and $1 \mathrm{~T}$ respectively, $F=14.4$, $p<0.001$; U11, 0.8 (0.6 to 1.1$)$ and 0.8 (0.6 to 1.0 ), $2 \mathrm{~T}$ and $1 \mathrm{~T}$ respectively, $\mathrm{X}^{2}=28.5, p<0.001 ; \mathrm{U} 15,0.7$ (0.4 to 0.9$)$ and $0.6(0.4$ to 0.9$), 2 \mathrm{~T}$ and $1 \mathrm{~T}$ respectively, $F=12.6, p<0.001$; U17, $0.3(0.1$ to 0.5$)$ and 0.4 (0.2 to 0.6$), 2 \mathrm{~T}$ and $1 \mathrm{~T}$ respectively, $F=4.82, p \leq$ 0.05 ; U19, 0.2 ( 0.0 to 0.4 ) and 0.4 (0.2 to 0.6$), 2 \mathrm{~T}$ and $1 \mathrm{~T}$ respectively, $F=4.37, p \leq 0.05$ ] when playing with limited touches, apart from playing with $2 \mathrm{~T}$ in the U13 [0.7 (0.5 to 1.0$)$ for $1 \mathrm{~T}, F=15.0, p<0.001]$ that did not reveal significant effects. In contrast, small to moderate decreases were identified in the distance covered while jogging across the different age groups [U9, $-0.4(-0.5$ to -0.2$)$ and $-0.5(-0.7$ to $-0.4), 2 \mathrm{~T}$ and $1 \mathrm{~T}$ respectively, $F=14.3, p<0.001$; $\mathrm{U} 11,-1.0(-1.2$ to -0.7$)$ and $-1.0(-1.3$ to -0.8$)$, $2 \mathrm{~T}$ and $1 \mathrm{~T}$ respectively, $F=40.0, p<0.001 ; \mathrm{U} 15,-0.6$ $(-0.8$ to -0.4$)$ and $-0.4(-0.6$ to -0.2$), 2 \mathrm{~T}$ and $1 \mathrm{~T}$ respectively, $F=10.5, p<0.001 ; \mathrm{U} 17,-0.4(-0.6$ to $-0.2)$ and $-0.5(-0.7$ to -0.2$), 2 \mathrm{~T}$ and $1 \mathrm{~T}$ respectively, $F=6.62, p<0.01 ; \mathrm{U} 19,-0.3(-0.4$ to -0.1$)$ and $-0.4(-0.6$ to -0.2$), 2 \mathrm{~T}$ and $1 \mathrm{~T}$ respectively, $F=5.33, p<0.01]$, apart from playing with $2 \mathrm{~T}$ in the U13 [-1.0 $(-1.2$ to -0.8$) \quad F=83.42, p<0.001]$. 
Table 3. Descriptive and statistical analysis for the physical variables according to SSG rule and age groups.

\begin{tabular}{|c|c|c|c|c|c|c|c|}
\hline \multirow{2}{*}{\multicolumn{2}{|c|}{ Physical Variables }} & \multicolumn{3}{|l|}{ SSG conditions } & \multicolumn{2}{|c|}{ Difference in means $( \pm 90 \% \mathrm{CL})$} & \multirow[b]{2}{*}{$P$} \\
\hline & & $\begin{array}{l}\text { Free } \\
(\text { Mean } \pm S D)\end{array}$ & $\begin{array}{l}2 \text { Touches } \\
\text { (Mean } \pm S D \text { ) }\end{array}$ & $\begin{array}{l}\text { I Touch } \\
\text { (Mean } \pm \text { SD) }\end{array}$ & $\begin{array}{l}\text { Free vs } \\
2 \text { Touches }\end{array}$ & $\begin{array}{l}\text { Free vs } \\
\text { I Touch }\end{array}$ & \\
\hline \multirow[t]{4}{*}{ U9 } & Total distance covered $(\mathrm{m})$ & $332.37 \pm 57.85$ & $312.92 \pm 68.99$ & $30 I . I \pm 55.35$ & $-19.46 \pm 9.54$ & $-32.24 \pm 10.36$ & $<0.00 \mathrm{I}^{\mathrm{a}, \mathrm{b}}$ \\
\hline & Walking (m) & $59.13 \pm 10.37$ & $63.42 \pm 13.35$ & $66.37 \pm 12.10$ & $4.29 ; \pm 2.13$ & $7.25 ; \pm 2.33$ & $<\left.0.00\right|^{a, b}$ \\
\hline & Jogging $(m)$ & $257.63 \pm 60.23$ & $233.42 \pm 70.24$ & $223.52 \pm 59.27$ & $-24.21 ; \pm 9.83$ & $-34.1 \mathrm{I} ; \pm 11.1 \mathrm{I}$ & $<0.001^{a, b}$ \\
\hline & Running $(\mathrm{m})$ & $15.62 \pm 14.59$ & $15.86 \pm 15.47$ & $11.09 \pm 9.77$ & $0.24 \pm 3.34$ & $-4.53 \pm 3.61$ & $>0.05$ \\
\hline \multirow[t]{4}{*}{ UII } & Total distance covered $(\mathrm{m})$ & $389.03 \pm 48.91$ & $336.02 \pm 45.65$ & $331.72 \pm 48.3$ & $-53.01 \pm 10.7$ & $-57.31 \pm 10.09$ & $<\left.0.00\right|^{\mathrm{a}, \mathrm{b}}$ \\
\hline & Walking $(\mathrm{m})$ & $48.28 \pm 12.30$ & $59.43 \pm 13.53$ & $58.93 \pm 13.34$ & $11.15 ; \pm 2.86$ & $10.64 ; \pm 2.80$ & $<0.00 \mathrm{I}^{\mathrm{a}, \mathrm{b}}$ \\
\hline & Jogging $(\mathrm{m})$ & $311.19 \pm 48.13$ & $260.10 \pm 52.13$ & $257.76 \pm 53.14$ & $-51.09 ; \pm 12.56$ & $-53.43 ; \pm 11.75$ & $<\left.0.00\right|^{\mathrm{a}, \mathrm{b}}$ \\
\hline & Running $(\mathrm{m})$ & $29.56 \pm 22.02$ & $16.28 \pm 14.05$ & $|5.04 \pm| 4.6 \mid$ & $-13.28 \pm 5.18$ & $-|4.52 \pm 4.5|$ & $<0.00 \mathrm{I}^{\mathrm{a}, \mathrm{b}}$ \\
\hline \multirow[t]{4}{*}{ UI3 } & Total distance covered $(\mathrm{m})$ & $417.87 \pm 52.06$ & $410.25 \pm 45.17$ & $359.06 \pm 65.79$ & $-7.61 \pm 8.84$ & $-58.8 \pm 11.53$ & $<0.00 \mathrm{I}^{\mathrm{a}, \mathrm{b}}$ \\
\hline & Walking $(\mathrm{m})$ & $41.60 \pm 11.34$ & $42.54 \pm 9.59$ & $50.13 \pm 13.23$ & $0.94 ; \pm 2.53$ & $8.53 ; \pm 2.76$ & $<0.00 \mathrm{I}^{\mathrm{b}}$ \\
\hline & Jogging $(m)$ & $333.65 \pm 51.60$ & $325.57 \pm 44.6 \mathrm{I}$ & $277.49 \pm 62.95$ & $-8.08 ; \pm 9.49$ & $-56.16 ; \pm 11.86$ & $<0.00 I^{b}$ \\
\hline & Running $(\mathrm{m})$ & $42.07 \pm 20.8$ & $41.79 \pm 27.25$ & $31.45 \pm 21.87$ & $-0.28 \pm 5.8$ & $-10.63 \pm 4.39$ & $<0.01^{\mathrm{b}}$ \\
\hline \multirow[t]{4}{*}{ UI5 } & Total distance covered $(\mathrm{m})$ & $424.71 \pm 37.54$ & $403.12 \pm 37.86$ & $410.02 \pm 43.09$ & $-21.59 \pm 7.66$ & $-14.69 \pm 8.32$ & $<\left.0.00\right|^{\mathrm{a}, \mathrm{b}}$ \\
\hline & Walking (m) & $37.06 \pm 8.44$ & $42.56 \pm 7.07$ & $42.12 \pm 8.68$ & $5.50 ; \pm 2.05$ & $5.06 \pm 2.12$ & $<\left.0.00\right|^{a, b}$ \\
\hline & Jogging $(m)$ & $339.4 \pm 35.05$ & $317.61 \pm 32.75$ & $325.2 \pm 36.27$ & $-21.79 \pm 7.87$ & $-14.21 \pm 8.15$ & $<0.00 \mathrm{I}^{\mathrm{a}, \mathrm{b}}$ \\
\hline & Running $(m)$ & $48.24 \pm 26.19$ & $42.94 \pm 23.93$ & $42.7 \pm 27.24$ & $-5.3 \pm 6.29$ & $-5.54 \pm 6.97$ & $>0.05$ \\
\hline \multirow[t]{4}{*}{ UI7 } & Total distance covered $(\mathrm{m})$ & $427.52 \pm 39.21$ & $418.59 \pm 49.89$ & $406.59 \pm 46.63$ & $-8.92 \pm \mid 0.51$ & $-20.93 \pm 10.76$ & $<0.01^{a, b}$ \\
\hline & Walking (m) & $36.11 \pm 8.73$ & $38.94 \pm 10.09$ & $40.04 \pm 10.03$ & $2.83 ; \pm 2.0$ & $0.46 ; \pm 0.29$ & $<0.05^{\mathrm{a}, \mathrm{b}}$ \\
\hline & Jogging $(m)$ & $350.6 \mathrm{I} \pm 41.09$ & $334.26 \pm 48.33$ & $327.52 \pm 48.4 I$ & $-16.36 ; \pm 9.33$ & $-7.05 ; \pm 2.55$ & $<0.01^{\mathrm{a}, \mathrm{b}}$ \\
\hline & Running (m) & $40.58 \pm 20.68$ & $45.39 \pm 22.56$ & $39.03 \pm 20.38$ & $4.82 \pm 6.18$ & $-1.55 \pm 6.05$ & $>0.05$ \\
\hline \multirow[t]{4}{*}{ U19 } & Total distance covered $(\mathrm{m})$ & $444.94 \pm 51.24$ & $437.18 \pm 48.84$ & $429.33 \pm 49.57$ & $-7.76 \pm 9.32$ & $-15.61 \pm 10.59$ & $<0.05^{\mathrm{a}, \mathrm{b}}$ \\
\hline & Walking (m) & $34.84 \pm 9.49$ & $36.85 \pm 9.89$ & $38.19 \pm 8.90$ & $2.01 ; \pm 1.97$ & $3.35 ; \pm 1.93$ & $<0.05^{b}$ \\
\hline & Jogging $(\mathrm{m})$ & $352.08 \pm 42.72$ & $340.69 \pm 45.54$ & $334.14 \pm 42.5 I$ & $-1 \mathrm{I} .39 ; \pm 8.37$ & $-17.94 ; \pm 10.29$ & $<\left.0.0\right|^{\mathrm{a}, \mathrm{b}}$ \\
\hline & Running $(\mathrm{m})$ & $57.92 \pm 26.94$ & $59.65 \pm 30.55$ & $56.72 \pm 31.25$ & $1.73 \pm 7.86$ & $-1.19 \pm 6.28$ & $>0.05$ \\
\hline
\end{tabular}

CL: confidence limits.

${ }^{a}$ Significant differences between free and I touch $(\mathrm{p} \leq .05)$.

bignificant differences between free and 2 touches $(p \leq .05)$.
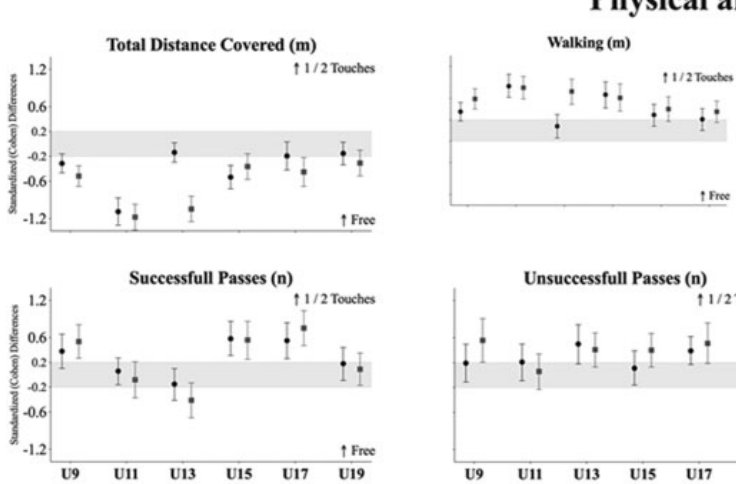

Physical and Technical Variables
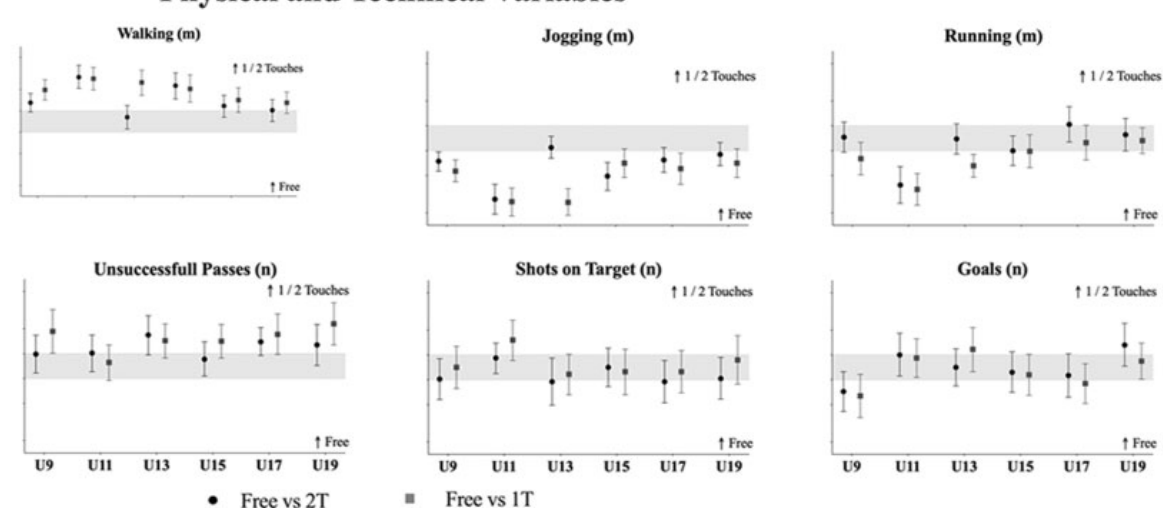

- Free vs 1T

Figure 2. Standardized (Cohen) differences in physical and technical variables according to the rules modification (free, 2 T, I T) in the different age groups. Error bars indicate uncertainty in the true mean changes with $90 \%$ confidence intervals.

The distance covered while running revealed moderate decreases when limiting the touches in the U11 $[-0.8$ $(-1.2$ to -0.5$)$ and $-0.9(-1.1$ to -0.6$), 2 \mathrm{~T}$ and $1 \mathrm{~T}$ respectively, $\left.\mathrm{X}^{2}=23.9, p<0.001\right]$ and small decreases in the $\mathrm{U} 13\left[-0.5(-0.7\right.$ to -0.3$\left.), \mathrm{X}^{2}=11.8, p<0.01\right]$ when playing with $1 \mathrm{~T}$ comparatively to the FP.

\section{Effects of manipulating the number of touches on the technical performance}

The effects on the technical variables when manipulating the number of touches (free vs $1 / 2$ touches) on the different age groups are presented on the Table 4 and 
Table 4. Descriptive and statistical analysis for the technical variables according to SSG rule and age groups.

\begin{tabular}{|c|c|c|c|c|c|c|c|}
\hline & & \multicolumn{3}{|c|}{ SSG conditions } & \multicolumn{2}{|c|}{ Difference in means $( \pm 90 \% \mathrm{CL})$} & \multirow[b]{2}{*}{$p$} \\
\hline \multicolumn{2}{|c|}{ Technical variables } & $\begin{array}{l}\text { Free } \\
(\text { Mean } \pm S D)\end{array}$ & $\begin{array}{l}2 \text { Touches } \\
(\text { Mean } \pm S D)\end{array}$ & $\begin{array}{l}\text { I Touch } \\
(\text { Mean } \pm S D)\end{array}$ & $\begin{array}{l}\text { Free vs } \\
2 \text { Touches }\end{array}$ & $\begin{array}{l}\text { Free vs } \\
\text { I Touch }\end{array}$ & \\
\hline \multirow[t]{4}{*}{ U9 } & $N .^{\circ}$ of successful passes (n) & $1.29 \pm 1.32$ & $1.79 \pm 1.07$ & $2.0 \pm 1.46$ & $0.50 \pm 0.36$ & $0.7 I ; \pm 0.36$ & $<0.01^{\mathrm{a}, \mathrm{b}}$ \\
\hline & $\mathrm{N}^{\circ}$ of unsuccessful passes $(\mathrm{n})$ & $0.65 \pm 0.96$ & $0.85 \pm 0.90$ & $1.25 \pm 1.28$ & $0.21 \pm 0.33$ & $0.6 ; \pm 0.38$ & $<0.05^{b}$ \\
\hline & $\mathrm{N}^{\circ}$ of shots-on-target $(\mathrm{n})$ & $0.29 \pm 0.65$ & $0.19 \pm 0.39$ & $0.29 \pm 0.54$ & $-0.10 \pm 0.18$ & $0.0 ; \pm 0.19$ & $>0.05$ \\
\hline & $N^{\circ}$ of goals scored $(n)$ & $0.42 \pm 0.74$ & $0.19 \pm 0.49$ & $0.15 \pm 0.46$ & $-0.23 \pm 0.19$ & $-0.27 ; \pm 0.20$ & $>0.05$ \\
\hline \multirow[t]{4}{*}{ UII } & $\mathrm{N}^{\circ}$ of successful passes $(\mathrm{n})$ & $2.46 \pm 1.71$ & $2.56 \pm 1.79$ & $2.31 \pm 1.94$ & $0.10 \pm 0.40$ & $-0.15 ; \pm 0.54$ & $>0.05$ \\
\hline & $\mathrm{N}^{\circ}$ of unsuccessful passes $(\mathrm{n})$ & $1.04 \pm 1.11$ & $1.27 \pm 1.28$ & $\mathrm{I} .10 \pm 0.83$ & $0.23 \pm 0.32$ & $0.06 ; \pm 0.31$ & $>0.05$ \\
\hline & $\mathrm{N}^{\circ}$ of shots-on-target $(\mathrm{n})$ & $0.10 \pm 0.31$ & $0.17 \pm 0.38$ & $0.29 \pm 0.54$ & $0.06 \pm 0.10$ & $0.19 ; \pm 0.14$ & $>0.05$ \\
\hline & $N^{\circ}$ of goals scored $(n)$ & $0.13 \pm 0.33$ & $0.21 \pm 0.46$ & $0.19 \pm 0.39$ & $0.08 \pm 0.14$ & $0.06 ; \pm 0.13$ & $>0.05$ \\
\hline \multirow[t]{4}{*}{ UI3 } & $\mathrm{N}^{\circ}$ of successful passes $(\mathrm{n})$ & $3.67 \pm 1.84$ & $3.35 \pm 1.96$ & $2.83 \pm 2.16$ & $-0.3 \mathrm{I} \pm 0.52$ & $-0.83 ; \pm 0.57$ & $<0.05^{b}$ \\
\hline & $N^{\circ}$ of unsuccessful passes $(n)$ & $0.94 \pm 0.95$ & $1.63 \pm 1.54$ & $\mathrm{I} .50 \pm 1.49$ & $0.69 \pm 0.44$ & $0.56 ; \pm 0.38$ & $<0.05^{a}$ \\
\hline & $\mathrm{N}^{\circ}$ of shots-on-target $(\mathrm{n})$ & $0.38 \pm 0.64$ & $0.25 \pm 0.48$ & $0.31 \pm 0.47$ & $-0.13 \pm 0.21$ & $-0.06 ; \pm 0.18$ & $>0.05$ \\
\hline & $\mathrm{N}^{\circ}$ of goals scored $(\mathrm{n})$ & $0.15 \pm 0.36$ & $0.15 \pm 0.41$ & $0.27 \pm 0.49$ & $0.0 \pm 0.13$ & $0.13 ; \pm 0.15$ & $>0.05$ \\
\hline \multirow[t]{4}{*}{ UI5 } & $\mathrm{N}^{\circ}$ of successful passes $(\mathrm{n})$ & $3.17 \pm 1.85$ & $4.42 \pm 2.25$ & $4.35 \pm 2.16$ & $1.25 \pm 0.59$ & $\mathrm{I} .19 ; \pm 0.64$ & $<\left.0.00\right|^{a, b}$ \\
\hline & $\mathrm{N}^{\circ}$ of unsuccessful passes $(\mathrm{n})$ & $1.23 \pm 1.24$ & $1.38 \pm 1.06$ & $\mathrm{I} .75 \pm \mathrm{I} .48$ & $0.15 \pm 0.36$ & $0.52 ; \pm 0.35$ & $>0.05$ \\
\hline & $\mathrm{N}^{\circ}$ of shots-on-target $(\mathrm{n})$ & $0.33 \pm 0.60$ & $0.33 \pm 0.52$ & $0.29 \pm 0.54$ & $0.0 \pm 0.17$ & $-0.04 ; \pm 0.21$ & $>0.05$ \\
\hline & $N^{\circ}$ of goals scored $(n)$ & $0.25 \pm 0.60$ & $0.21 \pm 0.50$ & $0.19 \pm 0.45$ & $-0.04 \pm 0.17$ & $-0.06 ; \pm 0.18$ & $>0.05$ \\
\hline \multirow[t]{4}{*}{ UI7 } & $\mathrm{N}^{\circ}$ of successful passes $(\mathrm{n})$ & $3.75 \pm 1.98$ & $5.21 \pm 3.11$ & $5.75 \pm 2.60$ & $1.46 \pm 0.78$ & $2.0 ; \pm 0.74$ & $<0.001^{\mathrm{a}, \mathrm{b}}$ \\
\hline & $\mathrm{N}^{\circ}$ of unsuccessful passes $(\mathrm{n})$ & $1.13 \pm 0.79$ & $1.60 \pm 1.12$ & $\mathrm{I} .75 \pm 1.54$ & $0.48 \pm 0.28$ & $0.63 ; \pm 0.40$ & $<0.05^{a, b}$ \\
\hline & $\mathrm{N}^{\circ}$ of shots-on-target $(\mathrm{n})$ & $0.48 \pm 0.65$ & $0.33 \pm 0.52$ & $0.44 \pm 0.65$ & $-0.15 \pm 0.21$ & $-0.04 ; \pm 0.21$ & $>0.05$ \\
\hline & $N^{\circ}$ of goals scored $(n)$ & $0.29 \pm 0.50$ & $0.23 \pm 0.47$ & $0.17 \pm 0.43$ & $-0.06 \pm 0.17$ & $-0.13 ; \pm 0.15$ & $>0.05$ \\
\hline \multirow[t]{4}{*}{ UI9 } & $\mathrm{N}^{\circ}$ of successful passes $(\mathrm{n})$ & $4.56 \pm 2.37$ & $5.0 \pm 1.96$ & $4.79 \pm 2.87$ & $0.44 \pm 0.66$ & $0.23 ; \pm 0.64$ & $>0.05$ \\
\hline & $N^{\circ}$ of unsuccessful passes $(n)$ & $0.88 \pm 1.02$ & $1.25 \pm 1.0$ & $1.63 \pm 1.21$ & $0.38 \pm 0.36$ & $0.75 ; \pm 0.38$ & $<0.05^{b}$ \\
\hline & $N^{\circ}$ of shots-on-target $(n)$ & $0.48 \pm 0.77$ & $0.35 \pm 0.53$ & $0.56 \pm 0.77$ & $-0.13 \pm 0.24$ & $0.08 ; \pm 0.28$ & $>0.05$ \\
\hline & $N^{\circ}$ of goals scored $(n)$ & $0.23 \pm 0.56$ & $0.46 \pm 0.7 \mathrm{I}$ & $0.29 \pm 0.58$ & $0.23 \pm 0.22$ & $0.06 ; \pm 0.18$ & $>0.05$ \\
\hline
\end{tabular}

$\mathrm{CL}$ : confidence limits; $\mathrm{N}^{\circ}$ : number.

${ }^{a}$ Significant differences between free and I touch $(\mathrm{p} \leq .05)$.

bignificant differences between free and 2 touches $(\mathrm{p} \leq .05)$.

Figure 1. Effects on the number of successful passes were identified in the U9 [0.4 (0.1 to 0.7$)$ and $0.5(0.3$ to 0.8$), 2 \mathrm{~T}$ and $1 \mathrm{~T}$ respectively, $\left.\mathrm{X}^{2}=9.53, p<0.01\right]$, $\mathrm{U} 13\left[-0.4(-0.7\right.$ to -0.1$)$ for $\left.1 \mathrm{~T}, \mathrm{X}^{2}=6.00, p \leq 0.05\right]$, U15 [0.6 (0.3 to 0.9$)$ and $0.6(0.3$ to 0.9$), 2 \mathrm{~T}$ and $1 \mathrm{~T}$ respectively, $F=7.57, p<0.001]$, and U17 [0.6 (0.4 to $0.8)$ and 0.8 (0.5 to 1.1$), 2 \mathrm{~T}$ and $1 \mathrm{~T}$ respectively, $F=11.0, p<0.001]$. Accordingly, small increases in the number of successful passes while playing with $2 \mathrm{~T}$ in the U9, U15 and U17, while there were small to moderate increases when playing with $1 \mathrm{~T}$ in the $\mathrm{U} 9$, U15 and U17. In contrast, there were a small decrease in the number of successful passes in the U13 while playing under 1T. Apart from the U11 and U15, there were in general small to moderate increases in the number of unsuccessful passes when limiting the number of touches [U9, $0.6(0.2$ to 0.9$)$ for $1 \mathrm{~T}$, $\mathrm{X}^{2}=8.37, p \leq 0.05 ; \mathrm{U} 13,0.5(0.2$ to 0.8$)$ and $0.4(0.1$ to 0.7$), 2 \mathrm{~T}$ and $1 \mathrm{~T}$ respectively, $\mathrm{X}^{2}=5.85, p \leq 0.05$, U17, 0.4 (0.2 to 0.6$)$ and $0.5(0.2$ to 0.8$), 2 \mathrm{~T}$ and $1 \mathrm{~T}$ respectively, $\mathrm{X}^{2}=6.56, p \leq 0.05$; $\mathrm{U} 19,0.3$ (0.0 to 0.7$)$ and $0.7(0.3$ to 1.0$), 2 \mathrm{~T}$ and $1 \mathrm{~T}$ respectively, $\mathrm{X}^{2}=9.3, p$ $\leq 0.05$, specially while playing under $1 \mathrm{~T}$. In addition, no effects of limiting the players touches were identified on the number of shots-on-target and on goals scored.

\section{Discussion}

The data from this study revealed how different age groups and practice experiences affected the players tactical, physical, and technical-related performance when manipulating the number of touches during a $\mathrm{Gk}+4 \mathrm{vs} 4+\mathrm{Gk}$ SSG. In general, higher effects were found when comparing playing with only $1 \mathrm{~T}$ to the free-play.

\section{Effects of manipulating the number of touches on the tactical-positional behavior}

A novel focus in the present study, it was the inclusion of the players tactical-positional behavior when playing under limited touches. Interestingly, players from all age groups were able to maintain stable distances independently of the number of touches allowed. In fact, 
there were no significant differences in the players' distance to the team centroid, the opponent centroid, nearest teammate or even in the distance to the nearest opponent. These results are in line with those found in the available research, that revealed similar distances between players when manipulating the available space to perform ${ }^{21}$ or while adding corridor and sectorial lines to the pitch. ${ }^{23}$ These findings seems to suggest that players regulate their behavior as result of the distance to the teammates and opponents. However, despite having similar distances, different movement patterns were identified across the different age groups as result of players interaction with task constraints. For example, the U11 presented a higher lpwratio during the free condition, which suggest a higher use of the length. Accordingly, past research showed that younger age groups seem to adopt a more direct playing style of play. ${ }^{19,38}$ However, when limiting the players touches, a higher focus on width emerge, possibly as an attempt of the players to receive with more space. This higher use of width may justify the slight increase in average values of goals found by this age group, as it seems that it increases the possible angle to shot, and consequently, enhancing the opportunities to score. ${ }^{18}$ This intention of exploring the available space can be depicted from the spatial exploration index (SEI), which intends to provide information regarding the area explored by each player. Accordingly, while some age groups increased the area explored, mainly when playing at $1 \mathrm{~T}$ (e.g., U11 and U15), possibly as an attempt to create space to receive the ball with more time to decide, in turn, other age groups such as U13 decreased their SEI. Accordingly, this was the only age group that decreased the number of successful passes under $1 \mathrm{~T}$, while also increasing the average values of goals scored, which may suggest a trend to create fast goal scoring opportunities by using less players and focus more on vertical passes. This may justify the lower values of physical performance, especially for $1 \mathrm{~T}$ in this age group, as well as the higher longitudinal synchronization.

The results from the movement synchronization revealed interesting results. For instance, both U9 and U17 decreased their longitudinal synchronization, mainly when playing under $1 \mathrm{~T}$, in comparison to the FP condition. Under this scope, past studies exploring the players visual search exploratory behavior revealed that more expert players have less number of fixations locations but of higher duration compared to more novice players ${ }^{39}$ suggesting a higher ability to identify the most relevant information to unfold goal-directed behaviors. However, younger age groups are still developing and refining their motor repertoire ${ }^{40}$ and so it is possible that their focus is driven towards their motor execution when playing under $1 \mathrm{~T}$, detuning their movement synchronization from teammates. While it would be expected that older age groups, such as U17, adapted better to the game rules compared to younger age groups, in this study it was found a decrease in the team synchrony and more lost balls. Although speculative, it is possible that the U17 that participated in this study may possess lower skill-levels as it would be expected for their category. For example, the U15 and U17 players had almost the same playing experience ( $\sim 7$ years). These may also help to justify the results found in the U15, which shown in general positive adaptations when playing with limited touches.

\section{Effects of manipulating the number of touches on the physical performance}

Manipulating the number of touches allowed during SSG it is a common constraint used by coaches. Accordingly, this type of rule is mostly used to increase the task physical demands. In fact, the available literature has shown increases in the distance covered, specially at high intensity, when playing under limited touches. ${ }^{10-13}$ Different results were identified in the present study, as in general the players cover more total distance and distance while jogging and running when playing during the Free condition comparing with the $2 \mathrm{~T}$ and $1 \mathrm{~T}$ scenarios. On the one hand, these differences may be related with the type of task used in past studies, as possession or small-goals SSG seems to induce higher physical stimulus than SSG performed with goalkeepers. ${ }^{41}$ By other hand, the players experience level also plays a key role in these differences. Accordingly, amateur players seems to evidence higher intensities without touch limitations than when playing with limited touches under possession $\mathrm{SSG}^{14}$ or SSG performed with goalkeepers. ${ }^{15}$ Therefore, the differences in the present study compared with the ones available can be attributed to the difference between task conditions (possession vs small goals vs goalkeepers) and players experience (elite, amateur, youth).

\section{Effects of manipulating the number of touches on the technical performance}

In general, despite not all age groups presented significant differences in terms of their technical performance, the younger age groups seem to be more affected by the manipulation in the number of touches allowed. These effects may be linked with their lower ability to adjust their positioning on the environmental information (e.g., teammate and opponent movements), mainly when in interacting with other constraints, such as the number of touches. That is, players of this age group do not possess the same 
(a)

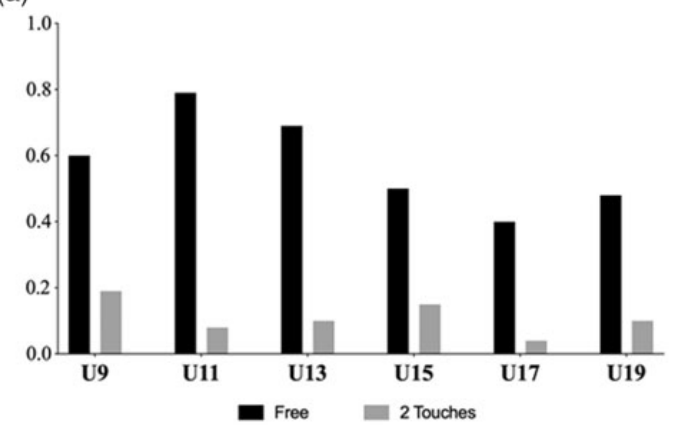

(b)

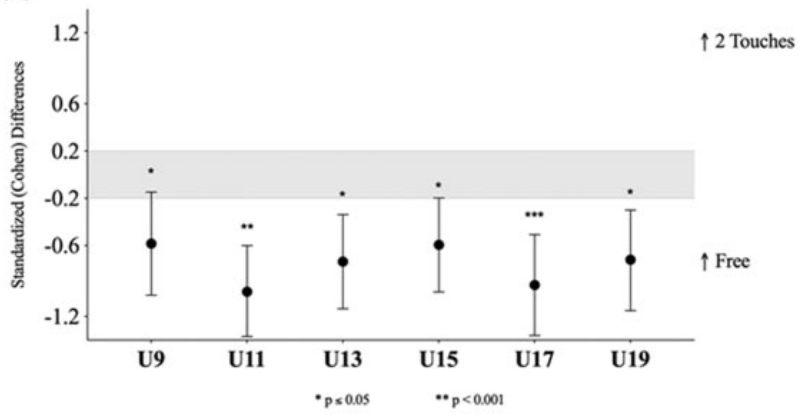

Figure 3. Average and standardized (Cohen) differences in the number of dribbles according to the SSG conditions (free, 2 touches) in the different age groups. Error bars indicate uncertainty in the true mean changes with $90 \%$ confidence intervals. (a) Average number of successfull dribbles (n) (b) Number of successfull dribbles (n).

perceptual and motor skills of older and more expert groups ${ }^{38,42}$ and therefore their attention may be driven to their individual motor capability to be able to cope with the task demands, affecting their overall performance. For instance, the result from the technical performance seems to strength this evidence, as younger age groups seems to be more affected in terms of passing performance when the number of touches were limited. While decreases in technical performance, such as passing performance, are consistent across the literature, ${ }^{10,11,13}$ its negative effects may be exacerbated in younger age groups, which may not be prepared to cope with the task requirements. In fact, younger players are still developing and refining their fundamental game skills mostly until the 13 -years of age ${ }^{40}$ and therefore, they might not possess the same ability to cope with the task demands leading to a decrease in the number of successful actions when playing with limited touches. Interestingly, the U9 revealed an increase in the number of successful actions under limited touches. This is a unique age group, characterized in general by a high number of touches per individual. Accordingly, players with more skills are likely to engage in more individual actions (e.g., dribbling), in turn, less skilled players are more likely to perform a considerable number of touches while trying to perceive the environment when pressured. This may justify the increase in the number of successful passes found in the U9 during the game situations under limited touches, as they were required to pass more often. Acquiring confidence and competence to move within the sports environment is important during the players development ${ }^{43}$ however, the results showed a considerably number of unsuccessful passes in all age groups and a decrease in the goals scored in the U9 while playing with limited touches. Accordingly, playing under limit touches increases the actions frequency ${ }^{44}$ however it also increases the players perceptual demands. ${ }^{10}$ When the players do not possess enough perceptual and motor skills that allows to cope with the task, it may limit their development. In addition, being able to successful perform and scoring goals is crucial to develop players confidence to move, and from the results, it is possible to identify that the U9 decrease considerably the amount of goals scored, which may limit their further commitment to sports. ${ }^{45}$ Therefore, coaches should carefully design the training tasks according to the players age groups to create appropriate learning and enrichment environments.

Playing with limited touches seems to be a key constraint to increase the players ability to perform under additional spatial and temporal demands, improving passing performance and to promote behavior adaptability. However, it also limits the time for action. For instance, a player that receive a ball with space to progress to the opponent's target may be forced to pass the ball as result of the limitation in the number of touches allowed. In addition, it may also inhibit the emergence of some specific technical actions. For example, Figure 3 pretends to show how playing with limited touches constrains the emergence of the player's dribble. In this image, it was possible to identify a decrease in the number of dribbles when playing under limited touches. From this perspective, coaches should be aware how important is to properly plan and design the training task rules to ensure an suitable learning environment for youth players where they are able to fully develop a wide and variable range of skills.

Whilst this study adds novel and important findings regarding to the effects of the number of allowed touches, some limitations should acknowledge. For example, previous studies shown that players of different expertise levels responded differently to this manipulation. In addition, the present study sample was composed by players belonging to different age groups from one academy in Portugal, in turn, 
different responses might have emerged if it was considered players from different countries or belonging to higher-ranking academies. Under this scope, the presence of such diverse age groups may also limit some comparisons between age categories, as for example, literature is still scarce in providing detailed information regarding speed thresholds according to the different development stages. Also, it would be interesting to analyze how players offensive and defensive actions were shaped by the number of touches allowed. Therefore, future research exploring the effects of limiting the number of touches may include offensive and defensive variables, such as the number of touches on the ball, completed passes distance or even space occupation according to have the possession or not, using ball tracking methods.

\section{Practical applications}

Constraining the number of allowed touches has been one of the most common rules used in association football. Players movement behavior results from their ability to perceive the information from the environment, which is different as result of their playing experience and level of performance. This study explored how players from a different age groups adjusted their movement behavior as response to limiting the number of ball touches. The effects identified in the positioning dynamics, lower physical performance, and some impairments in the players technical actions, may suggest that the younger age groups, specially the U9, may not possess enough perceptual and motor skills that allows them to successfully cope with the task demands when playing in this condition. In contrast, while also distinct movement patterns were identified in older age groups (U15-U19), their technical performance was less affected by the manipulation in the number of touches, suggesting that they are more able to perform under such constraints, especially the U19. Based on these considerations, younger players (U9-U13) should be less frequently exposed to limited touches, while playing under $2 \mathrm{~T}$ limitation seems to be more suitable to their development stage. In turn, older age groups (U15-U19) revealed a higher ability to adjust their movement behavior, which may suggest that coaches may use this rule to increase the perceptual demands while challenging the players to explored adaptive movement responses.

\section{Conclusions}

Overall, the results from this study highlights that different responses emerge as result of the number the touches manipulation during the SSG and with different effects on the different age groups. More specifically, modifying the number of ball touches mostly affected the players' physical and technical performances. Players covered less total distance covered when performing with limited touches, mainly as result of the lower distance covered while jogging and higher while walking. From the technical perspective, playing with limited touches contributed to more successful passes, but also increased unsuccessful ones. While the distance-related variables were less sensitive to the manipulation in the number of touches, in turn, players seem to adapt the coordination with the teammates and space explored as result of the number of touches allowed. The effects on the players physical, technical, and collective movement behavior were more evident when compared to the 1 touch condition.

As so, it is important to properly periodize the use of this constraint, especially in younger age groups, to ensure a variable and enrichment learning environment.

\section{Declaration of conflicting interests}

The author(s) declared no potential conflicts of interest with respect to the research, authorship, and/or publication of this article.

\section{Funding}

The author(s) declared the following potential conflicts of interest with respect to the research, authorship, and/or publication of this article: This work was supported by national funding through the Portuguese Foundation for Science and Technology, under the project UID/04045/2020.

\section{ORCID iDs}

Diogo Coutinho (D) https://orcid.org/0000-0001-6605-9505

Bruno Gonçalves (D) https://orcid.org/0000-0001-7874-4104

\section{References}

1. Caso $\mathbf{S}$ and van der Kamp J. Variability and creativity in small-sided conditioned games among elite soccer players. Psychol Sport Exerc 2020; 48: 101645.

2. Hill-Haas SV, Dawson B, Impellizzeri FM, et al. Physiology of small-sided games training in football: a systematic review. Sports Med 2011; 41: 199-220.

3. Bujalance-Moreno P, Latorre-Román P and GarcíaPinillos F. A systematic review on small-sided games in football players: acute and chronic adaptations. $J$ Sports Sci 2019; 37: 921-949.

4. Clemente F and Sarmento H. The effects of small-sided soccer games on technical actions and skills: a systematic review. $h m$ 2020; 21: 100-119.

5. Coito N, Davids K, Folgado H, et al. Capturing and quantifying tactical behaviors in small-sided and conditioned games in soccer: a systematic review. Res $Q$ Exerc Sport 2020; $\mathbf{\square}: 1-15$.

6. Davids K, Araújo D, Correia V, et al. How small-sided and conditioned games enhance acquisition of movement 
and decision-making skills. Exerc Sport Sci Rev 2013; 41: 154-161.

7. Machado JC, Barreira D, Teoldo I, et al. How does the adjustment of training task difficulty level influence tactical behavior in soccer? Res $Q$ Exerc Sport 2019; 90: 403-416.

8. Travassos B, Duarte R, Vilar L, et al. Practice task design in team sports: representativeness enhanced by increasing opportunities for action. $J$ Sports Sci 2012; 30: 1447-1454.

9. Newell KM. Constraints on the development of coordination. Berlin: Springer, 1986, pp.341-360.

10. Dellal A, Lago-Penas C, Wong del P, et al. Effect of the number of ball contacts within bouts of 4 vs. 4 smallsided soccer games. Int J Sports Physiol Perform 2011; 6: $322-333$.

11. Dellal A, Owen A, Wong DP, et al. Technical and physical demands of small vs. large sided games in relation to playing position in elite soccer. Hum Mov Sci 2012; 31: 957-969.

12. Giménez JV, Liu H, Lipińska P, et al. Physical responses of professional soccer players during 4 vs. 4 small-sided games with mini-goals according to rule changes. Biol Sport 2018; 35: 75-81.

13. Torreblanca-Martínez V, Cordero-Ojeda R and GonzálezJurado JA. Análisis de variables condicionales y técnicotácticas mediante juegos reducidos en futbolistas semiprofesionales (analysis of physical and technical-tactical demands through small-sided games in semi-professional football players). Retos 2018; 35: 87-90.

14. Casamichana D, Suarez-Arrones L, Castellano J, et al. Effect of number of touches and exercise duration on the kinematic profile and heart rate response during smallsided games in soccer. J Hum Kinet 2014; 41: 113-123.

15. Román-Quintana JS, Casamichana D, Castellano J, et al. The influence of ball-touches number on physical and physiological demands of large-sided games. Kinesiology 2013; 45: 171-178.

16. Dellal A, Hill-Haas S, Lago-Penas C, et al. Small-sided games in soccer: amateur vs. professional players' physiological responses, physical, and technical activities. $J$ Strength Cond Res 2011; 25: 2371-2381.

17. Gonçalves B, Marcelino R, Torres-Ronda L, et al. Effects of emphasising opposition and cooperation on collective movement behaviour during football smallsided games. J Sports Sci 2016; 34: 1346-1354.

18. Folgado H, Bravo J, Pereira P, et al. Towards the use of multidimensional performance indicators in football small-sided games: the effects of pitch orientation. $J$ Sports Sci 2019; 37: 1064-1071.

19. Olthof S, Frencken W and Lemmink K. The older, the wider: on-field tactical behavior of elite-standard youth soccer players in small-sided games. Hum Mov Sci 2015; 41: 92-102.

20. Folgado H, Lemmink KA, Frencken W, et al. Length, width and centroid distance as measures of teams tactical performance in youth football. Eur J Sport Sci 2014; 14 Suppl 1: S487-92.
21. Gonçalves B, Esteves P, Folgado H, et al. Effects of pitch area-restrictions on tactical behavior, physical and physiological performances in soccer large-sided games. $J$ Strength Cond Res 2017; 31: 2390-2408.

22. Coutinho D, Gonçalves B, Travassos B, et al. Different marks in the pitch constraint youth players' performances during football small-sided games. Res $Q$ Exerc Sport 2020; 91: 15-23.

23. Coutinho D, Gonçalves B, Travassos B, et al. Effects of pitch spatial references on players' positioning and physical performances during football small-sided games. $J$ Sports Sci 2019; 37: 741-747.

24. Aguiar M, Goncalves B, Botelho G, et al. Footballers' movement behaviour during 2-, 3-, 4- and 5-a-side smallsided games. J Sports Sci 2015; 33: 1259-1266.

25. Coutinho D, Santos S, Gonçalves B, et al. The effects of an enrichment training program for youth football attackers. Plos One 2018; 13: e0199008.

26. Folgado H, Duarte R, Fernandes O, et al. Competing with lower level opponents decreases intra-team movement synchronization and time-motion demands during pre-season soccer matches. Plos One 2014; 9: e97145.

27. Folgado H, Duarte R, Marques P, et al. The effects of congested fixtures period on tactical and physical performance in elite football. J Sports Sci 2015; 33: 1238-1247.

28. Palut $\mathrm{Y}$ and Zanone PG. A dynamical analysis of tennis: concepts and data. J Sports Sci 2005; 23: 1021-1032.

29. Travassos B, Araújo D, Duarte R, et al. Spatiotemporal coordination behaviors in futsal (indoor football) are guided by informational game constraints. Hum Mov Sci 2012; 31: 932-945.

30. Travassos B, Araujo D, Vilar L, et al. Interpersonal coordination and ball dynamics in futsal (indoor football). Hum Mov Sci 2011; 30: 1245-1259.

31. Santos S, Coutinho D, Gonçalves B, et al. Effects of manipulating ball type on youth footballers' performance during small-sided games. Int J Sports Sci Coach 2020; 15: $170-183$.

32. Figueira B, Gonçalves B, Masiulis N, et al. Exploring how playing football with different age groups affects tactical behaviour and physical performance. Biol Sport 2018; 35: 145-153.

33. Olthof S, Frencken W and Lemmink K. Match-derived relative pitch area changes the physical and team tactical performance of elite soccer players in small-sided soccer games. J Sports Sci 2018; 36: 1557- 1557.

34. Liu H, Gómez M-A, Gonçalves B, et al. Technical performance and match-to-match variation in elite football teams. J Sports Sci 2015; 34: 1-10.

35. O'Donoghue P. Research methods for sports performance analysis. London: Routledge, 2010, 278 p.

36. Kleiven $\varnothing$, Bjørkavoll-Bergseth MF, Omland $\mathrm{T}$, et al. Progressive statistics for studies in sports medicine and exercise science. Med Sci Sports Exercise 2020; 30: 1024-1013. 
37. Hopkins WG. Spreadsheets for analysis of controlled trials, crossovers and time series. Sportscience 2017; 2017: 1-4.

38. Travassos B, Coutinho D, Gonçalves B, et al. Effects of manipulating the number of targets in U9, U11, U15 and U17 futsal players' tactical behaviour. Hum Mov Sci 2018; 61: 19-26.

39. Savelsbergh GJ, Williams AM, Van der Kamp J, et al. Visual search, anticipation and expertise in soccer goalkeepers. J Sports Sci 2002; 20: 279-287.

40. Stafford I. Coaching for long-term athlete development: to improve participation and performance in sport. Leeds: Coachwise Business Solutions on behalf Sports Coach UK; 2005.

41. Castellano J, Casamichana D and Dellal A. Influence of game format and number of players on heart rate responses and physical demands in small-sided soccer games. J Strength Cond Res 2013; 27: 1295-1303.
42. Kannekens R, Elferink-Gemser MT and Visscher C. Positioning and deciding: key factors for talent development in soccer. Scand J Med Sci Sports 2011; 21: 846-852.

43. Santos S, Memmert D, Sampaio J, et al. The spawns of creative behavior in team sports: a creativity developmental framework. Front Psychol 2016; 7: 1282.

44. Brito R, Bredt S, Greco P, et al. Influence of limiting the number of ball touches on players' tactical behaviour and network properties during football small-sided games. Int J Perform Anal Sport 2019; 19: 999-1010.

45. Duda JL. and Treasure Dc Motivational processes and the facilitation of performance, persistence, and well-being in sport. In: William M (ed.) Applied sport psychology: personal growth to peak performance. New York, NY: Mcgraw hill higher education, 2006, pp. 57-81. 